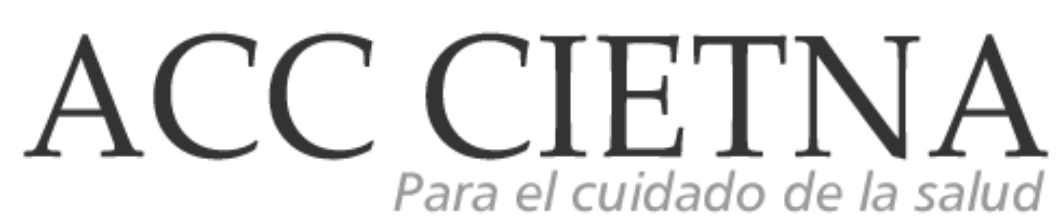

https://doi.org/10.35383/cietna.v4i2.19

\title{
Viviendas saludables para el Turismo Rural Comunitario en el caserío Huaca de Piedra, íllimo
}

\author{
Barturén Chicoma Magaly Nataly , Díaz Vásquez, Maribel Albertina²
}

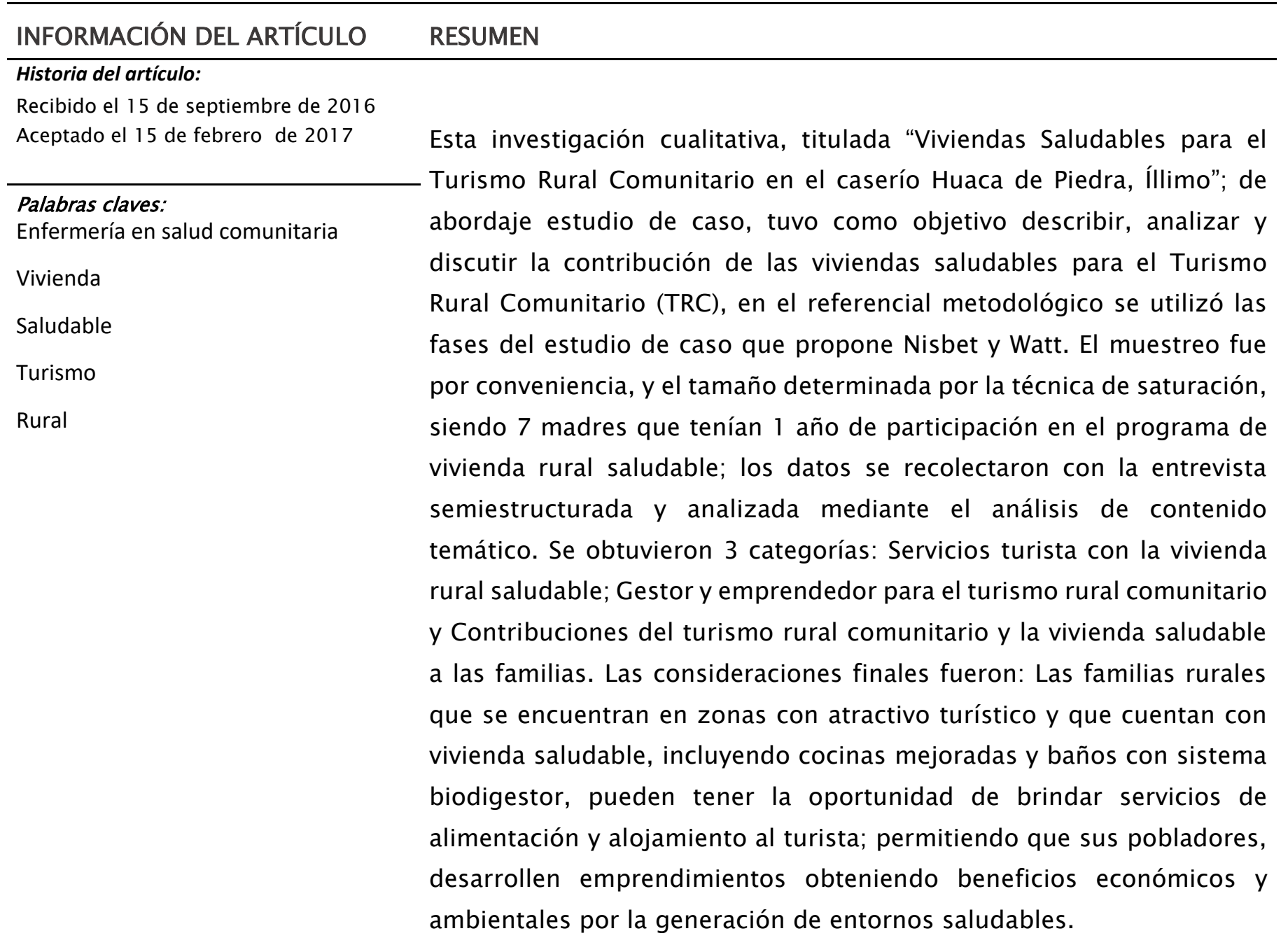

\footnotetext{
${ }^{1}$ Licenciada en Enfermería. Monitora de Salud Colegio de Alto Rendimiento COAR - San Martín, Perú. Email: Maga.3088@hotmail.com

${ }^{2}$ Magister en Enfermería. Docente de la Escuela de Enfermería de la Universidad Católica Santo Toribio de Mogrovejo, Chiclayo, Perú. Email: diaz@usat.edu.pe
} 
Healthy homes for Tourism Rural Community in Huaca de Piedra, Illimo

ABSTRACT

Keywords:

Nursing in community health Housing

Healthy

Tourism

Rural
The qualitative research, titled "Healthy Housing for Community Rural Tourism in the Huaca de Piedra hamlet, Íllimo"; The aim of this study was to describe, analyze and discuss the contribution of healthy housing to Community Rural Tourism (CRT). In the methodological framework, the phases of the case study proposed by Nisbet and Watt were used. The sampling was for convenience, and the size determined by the saturation technique, being 7 mothers who had 1 year of participation in the program of healthy rural housing; the data were collected with the semi-structured interview and analyzed through the thematic content analysis. Three categories were obtained: Tourist services with healthy rural housing; Manager and entrepreneur for rural community tourism and Contributions of community rural tourism and healthy housing to families. The final considerations were: Rural families in areas with attractive tourism and healthy housing, including improved kitchens and bathrooms with a biodigestor system, may have the opportunity to provide food and lodging services to the tourist; allowing its inhabitants, to develop enterprises obtaining economic and environmental benefits for the generation of healthy environments.

\section{Introducción}

La pobreza es un problema mundial en grandes proporciones, casi la mitad de los seis millones vive con menos de 2 dólares al día y la quinta parte de esta población subsistió con menos de 1 dólar, conllevando a que estas personas no tengan oportunidades, se transformen en personas vulnerables ante las enfermedades, la violencia y los desastres naturales. El Banco Mundial aseguró que 44 millones de personas han caído en la pobreza desde junio del 2010, en la actualidad unos 1200 millones de seres humanos viven en la indigencia?. A pesar de ello, en Perú, en el año 2011 la pobreza se redujo a 30,8\%; sin embargo, UNICEF alertó en un estudio que la pobreza en el Perú alcanza a $78 \%$ de la población indígena de entre 3 y 17 años, comparado con el $40 \%$ de los que tienen el castellano como lengua materna ${ }^{2}$.

En la región Lambayeque, el índice de pobreza no disminuyó desde hace cuatro años, el 
departamento se ubica en el puesto diez en el mapa de pobreza en el país, esto según fuente del INEI-Lambayeque; los distritos de Inkawasi, Kañaris, Túcume, Mórrope y Salas continúan considerándose entre los que registran alto índice de población pobre, ocasionando de este modo un deterioro en las necesidades básicas de la persona y familia, viéndose en peligro su salud y afectando su calidad de vida ${ }^{3}$. Asimismo, en el distrito de íllimo del departamento de Lambayeque, existen 12 caseríos, con una densidad de 91 habitantes por $\mathrm{km} 2$, entre sus principales centros poblados encontramos al caserío Huaca de Piedra, una zona rural donde muchos de sus pobladores gozan de una vivienda saludable, elemento estratégico para la mejora de su familia, comunidad y el turismo rural comunitario que emerge como una iniciativa económica. Por ello, hoy la existencia de proyectos que contribuyen a que las familias puedan fomentar la vivienda saludable y con ella generen mayores ingresos económicos; pues es escenario de gastronomía, artesanía y de alojamiento a turistas. Las familias han trabajado en el Programa de Vivienda Rural Saludable por tres años y hoy cuentan con baños dignos, cocinas mejoradas además de mejores condiciones de higiene y orden en los alojamientos, conllevando a una mejora de calidad de vida de los habitantes.

Una vivienda saludable es aquel espacio físico que propicia condiciones satisfactorias para la persona y la familia, reduciendo al máximo los factores de riesgo existentes en su contexto geográfico, económico y social; por ejemplo: Garantiza seguridad y protección, facilita el descanso, presenta condiciones adecuadas para el almacenamiento, preparación y consumo de los alimentos, suministra los recursos para la higiene personal, doméstica y el saneamiento, entre otros 4 .
Las condiciones de la vivienda fueron reconocidas como uno de los principales determinantes sociales de la salud humana, ya que pueden promover la salud física, mental y social de sus residentes; por lo tanto, se asegura que al tener una vivienda saludable permitirá que las familias puedan tener un comportamiento más saludable, además de contribuir para la salud, la cultura, el turismo y desarrollo sostenible ${ }^{4}$, es por ello que a las familias del Caserío Huaca de Piedra se buscó enseñarles a cómo utilizar su vivienda saludable para beneficio de ellos mismos y del turismo que poseen en medio de la comunidad rural. Por otro lado, las zonas rurales tienen gran variedad de atractivos turísticos, los mismos que se pueden brindar dentro de un marco de Turismo Rural Comunitario (TRC). En efecto es una propuesta que recién está tomando valor en Perú y que da mucha importancia a la salud comunitaria para generar entornos saludables en la comunidad, dando la oportunidad de satisfacer algunas necesidades básicas que tiene todo ser humano en el proceso de la vida. Así mismo, el TRC permite que las personas reciban visitantes, generando beneficios económicos, al brindar alojamiento, alimentación, venta de artesanías y productos que cultiva cada familia, entre otros servicios. A la vez que se genera un beneficio ambiental y social, toda vez que los turistas disfrutan de lugares saludables $y$ hermosos y las viviendas presentan diseños propios de su identidad cultural, lo que permite la oferta de este tipo de Turismo. A partir de esta realidad de planteo, la siguiente pregunta: ¿Cómo contribuyen las viviendas saludables al Turismo Rural Comunitario en el caserío Huaca de Piedraíllimo?, con el objetivo de describir, analizar y discutir la contribución de las viviendas saludables para el Turismo Rural Comunitario.

La vivienda es un lugar indispensable para la vida, necesaria para el desarrollo de las personas y la familia ya que brinda seguridad, protección, 
intimidad y contribuye al bienestar de todas las personas, ello implica reducir al máximo los factores de riesgos, es por eso que el actuar de la enfermera comunitaria debe buscar hacer sostenible sus proyectos y propuestas, mediante otras estrategias que den sostenibilidad al programa.

Las viviendas saludables son un aporte para el TRC, generando rentabilidad económica y por ende una mejora de la canasta familiar, reduciendo al máximo los riesgos que puedan perjudicar la salud de la familia y todo esto gracias a actividades productivas como: la gastronomía, hospedajes, guiados turísticos, etc. Por otro lado, la participación comunitaria es un proceso mediante el cual, las personas adquieren un sentido de responsabilidad con respecto a su propio bienestar $y$ el del grupo, contribuyendo conscientemente y constructivamente en el proceso de desarrollo.

\section{Metodología}

La presente investigación fue de tipo cualitativa 5 , pues permitió develar y comprender el fenómeno en su entorno natural, por lo que fue necesario que la investigadora permanezca en el escenario durante periodos prolongados, estudiando de forma holística a los sujetos de investigación y a la comunidad en la que habitan. El abordaje fue el estudio de caso, por permitir investigaciones a profundidad de una sola entidad o de una serie reducida de entidades ${ }^{6}$. Los sujetos de investigación, fueron 7 madres de familia del Caserío Huaca de Piedra, del distrito de íllimo, obtenidas por la técnica de saturación; así mismo para obtener una muestra homogénea se estableció como criterios de inclusión: Haber participado como mínimo un año en el programa Viviendas Rural Saludable, participación voluntaria y activa y saber leer y escribir, se excluyó a aquellos que participaron en la prueba mi piloto.
El lugar donde se realizó la investigación fue en íllimo, ubicado en la parte central de la Chala Lambayecana, en el valle del rio La Leche, territorialmente es el más pequeño de la provincia de Lambayeque y tiene $24.27 \mathrm{~km}^{2}$, cuenta con un clima cálido templado7. La hombres de la población se caracterizan por trabajar en la agricultura, ganadería y elaboración de adobe; mientras tanto, las mujeres en la preparación de chicha de jora; sus viviendas son amplias, se ubican en medio de la naturaleza y están construidas con material de adobe y quincha, contando dentro de ella con servicios básicos como agua, luz, baño y cocina mejorada. Los datos, se recolectaron mediante la técnica de entrevista semiestructurada 8 , y como instrumento se utilizó una guía de entrevista, que constó de dos partes; la primera con datos personales como: número de hijos, ingreso familiar mensual y por ultimo si uno de los integrantes de la familia están presentando alguna enfermedad. La segunda contenía tres preguntas abiertas relacionadas con el tema de investigación; la entrevista se aplicó en las mismas viviendas, en un ambiente libre de ruidos, la duración promedio fue de 25 minutos y para garantizar la credibilidad se usó un grabador de voz, mediante un MP3. Cabe mencionar que la guía de entrevista fue validada por juicio de expertos, que consistió en la revisión de tres expertos: dos docentes con más de ocho años de experiencia en investigación cualitativa y un experto en la temática, con más de doce años de experiencia laboral en el área y por piloto, en el mismo escenario de investigación.

Antes de iniciar la investigación, se contó con la aprobación del proyecto por el Comité Metodológico de la Escuela de Enfermería y del Comité de Ética en Investigación de la Faculta de Medicina, de la Universidad Católica Santo Toribio de Mogrovejo, en seguida se solicitó el permiso al teniente gobernador del caserío Huaca de Piedra 
del Distrito de íllimo, y luego se procedió a realizar las visitas casa por casa para identificar a las familias que cumplían con los criterios de inclusión y a quienes accedían se le informaba con palabras sencillas y claras sobre la investigación, pactando con ellos la fechas y hora de la entrevista, el mismo que se formalizaba con la firma del consentimiento informado. Las entrevistas fueron realizadas por la misma investigadora y trascritas conforme se ejecutaban, esto permitió mejorar el proceso de recolección de datos. Asimismo se utilizó un diario de campo, donde se anotaron todas las manifestaciones no verbales de los participantes, así como las características y/o circunstancias del contexto. Los datos se analizaron mediante el análisis temático, el cual se define como el procedimiento que consiste en descubrir los núcleos de sentido que componen una comunicación, cuya presencia o frecuencia signifique alguna cosa para el objetivo analítico trazado, se constituye por tres etapas: Preanálisis, codificación y categorización ${ }^{9}$.

En toda la investigación se respetó los principios éticos de Sgreccia dentro de los cuales tenemos: El principio de defensa de la vida física, principio de libertad y responsabilidad, principio de sociabilidad y subsidiariedad. La calidad científica estuvo sustentada por la práctica los criterios de rigor científico de Lincoln y Guba: Credibilidad, transferibilidad y confirmabilidad ${ }^{10}$.

\section{Resultados, análisis y discusión}

CATEGORÍA I: Servicios al turista con la vivienda saludable

La vivienda saludable es aquel espacio físico de residencia que propicia condiciones satisfactorias para la persona y la familia, reduciendo al máximo los factores de riesgo existentes en su contexto geográfico, económico, social y técnico ${ }^{1}$. Como componente genera ambientes saludables e involucra activamente a todos los miembros de la familia, les permite ser protagonistas de su propio desarrollo, teniendo como punto de inicio el logro de una vivienda digna y una salud física, mental y social más sana, a través de la adopción de nuevos estilos de vida saludables ${ }^{12}$.

Ante esto se recalca la satisfacción dada en cada una de las viviendas saludables ubicadas en el caserío Huaca de Piedra, íllimo que con su esfuerzo y perseverancia de cada uno de los integrantes de las familias, hoy cuentan con una vivienda digna y saludable, logrando un desarrollo personal y colectivo, favoreciendo el turismo rural comunitario.

1.1. Potencial del servicio de alimentación a base de productos locales y manipulación de alimentos.

La alimentación es hija indiscutible de la geografía, de la economía y la historia. El ser vivo se inserta históricamente en la ecología de su hábitat para aprovecharse de sus recursos y satisfacer sus necesidades ${ }^{13}$.

En la actualidad la gastronomía es parte esencial del patrimonio cultural intangible de los pueblos. La alimentación es una actividad esencial para los seres humanos y dentro de la cultura es un aspecto claro y decisivo de las sociedades. La comida da un sentido de pertenecía colectiva, de cohesión social e identidad ${ }^{14}$.

El caserío Huaca de Piedra, además de ser un lugar cultural es natural, cuenta con una extensa gama de productos nativos vegetales, fauna y recursos hidrobiológicos, recursos con los que la enfermera comunitaria trabaja conjuntamente con la familia, cuando brinda la educación para la salud, en las que procura que las madres que son las que reciben las sesiones educativas, aprendan a explotar sus recursos y de este modo sean los autores de la mejora y progreso de su propia salud, familia y comunidad. 
Así tenemos, por ejemplo que el loche es un fruto emblemático de la cultura Lambayecana, cultivado desde la cultura Moche hasta la actualidad; si bien es cierto, se produce a lo largo de la costa, pero sus productos no tienen el sabor y aroma de los loches cultivados en nuestra región. íllimo es uno de los principales distritos donde se cultiva el loche ${ }^{14}$. Esta subcategoría se fundamenta, en las siguientes unidades de significado:

“...Para primero ofrecer tengo que elegir un plato que uno sepa cocinar muy bien y que sea un plato que tenga alimentos que cosechamos por acá como el loche, así los que vienen van a conocer más de nuestra comida, tengo que prepararlo rico y que las cosas que he comprado para preparar sean del día así la comida no sale malograda..." (Clavel)

“...Les daría la bienvenida y luego les presentaría como una lista donde están escritos todos los platos que uno sabe cocinar, cuando elijan, me voy al mercado compro del ratito y comienzo a cocinarles, mi idea señorita es de enseñarles a cocinar la comida de aquí, por ejemplo un arroz con su cabrito acompañado de su chicha de jora, antes de eso veo mis alimentos que compro, tienen que estar frescos..." (Azucena)

Según la OMS hay diez reglas de oro en relación a la higiene para la manipulación de alimentos, se mencionan en primer lugar a elegir alimentos elaborados o producidos higiénicamente, cocinar bien los alimentos, guardar cuidadosamente los alimentos cocinados, consumir los alimentos inmediatamente después de cocinados, evitar el contacto entre alimentos crudos y cocidos, realizar un estricto lavado de manos antes y después de los alimentos, mantener muy limpias todas las superficies de la cocina, mantener los alimentos fuera del alcance de roedores, insectos y otros animales y utilizar agua potable ${ }^{15}$.

A parte de utilizar los alimentos de la zona, es muy importante el lavado de manos, y todas las medidas higiénicas con los alimentos, a fin de garantizar la salud de los visitantes y el de la familia misma. Los testimonios se presentan así:
“...Antes de preparar los platos típicos, tengo que escoger que les voy a preparar, tiene que ser algo que sea del lugar donde vivimos, por ejemplo cabrito más su chicha de jora, tengo que escoger bien los alimentos, lavarlos cuidadosamente, debo de tener todo ordenado en mi cocina y al momento de prepararlo primero tengo que lavarme las manos con agua y jabón..." (Margarita)

“...Les prepararía algo rico, que este con todos sus condimentos y este bien sazonado, cocinaría algo como un arroz con cabrito o arroz con pato, pero todo acompañado con su jarra de chicha de jora. Antes de preparar, me debo de lavar las manos a cada rato, porque no sé si ha visto señorita, pero en la televisión sale que nos enfermamos de diarreas porque preparamos las comidas con las manos sucias, por eso me lavaría a cada rato..." (Rosa)

En el presente estudio, no solo se develó que una de las potenciales actividades de servicio es la alimentación, sino que teniendo la afluencia de turistas que acuden constantemente a disfrutar del lugar, se incrementó el servicio de alojamiento, dándole la oportunidad a los visitantes, de sentir las mismas comodidades y facilidades que siente en su casa, pero en un ámbito más rural. Esto se discute en la siguiente subcategoría.

1.2 Estableciendo comodidades y limpieza al alojamiento rural dentro de un marco de servicio de calidad.

Se define alojamiento rural como al establecimiento ubicado en área rural y cuyas características principales responden a la identidad cultural y regional. Dentro de las clases de Hospedaje se mencionan desde un hotel cinco estrellas hasta un albergue rural, catalogándolo como establecimiento de hospedaje que presta servicio de alojamiento preferentemente en habitaciones comunes, a un determinado grupo de huéspedes que comparten uno o varios intereses y actividades afines. 
Los pobladores participantes en la investigación, tuvieron el privilegio de poder trabajar directamente con los servicios que requieren los visitantes, ofreciendo alojamiento con un servicio de calidad; para ello procuraron hacer de su vivienda un medio de armonía, seguridad y salud, cuidando adecuadamente cada espacio que les proporciona la casa en la que viven, para que luego puedan llevar sus prácticas saludables al servicio que prestarán a los turistas. La satisfacción y el desarrollo de los pobladores participantes en el proyecto se presentan en las siguientes manifestaciones:

\section{"...Participar y trabajar en Turismo a ayudado a que} mi familia y yo mejoremos mucho, siempre tengo que ir a las capacitaciones que no da el CENFOTUR y la ONG para aprender a cómo tratar a los que nos visitan, yo estoy encargada de dar la bienvenida junto a mi esposo a los turistas y de limpiar todos los días el alojamiento, todo esto ha servido para mi hogar también..." (Libido)

“...Sé que muchos turistas van a venir y estarán contentos por visitarnos, en las capacitaciones hemos aprendido a como tenerlo limpio, todo ordenadito, que comida cocinarles, como debemos tratar a los demás, también primeros auxilios, tengo un botiquín en mi casa para cualquier cosa que necesiten..." (Azucena)

Lograr una atmosfera y una ambientación especial forma parte de la comodidad en un alojamiento, no importa si está localizado en un área natural, en un pequeño pueblo o en alguna de las ciudades más importantes, tampoco si es algo rústico y sencillo. Uno de los pasos fundamentales es lograr una ambientación acogedora, distintiva, cuidada en la cual el huésped pueda ver y sentir que fue algo hecho con dedicación, cuidado y profesionalismo. Cada detalle debe estar pensado para hacer de la estadía del viajero una experiencia única ${ }^{16}$. Ante lo expuesto, se presentan los siguientes testimonios:
“...Los cuartos como dijeron en la capacitación tienen que ser A1, porque son para turistas. Tiene que haber ventilación, estar bonito y decorado, con su mosquetero por los mosquitos que hay en la noche, tener un baño limpio siempre, además debemos tener luz y agua ya que eso es lo principal para todos los días cuando vengan por aquí..." (Rosa)

“...Mi casa es grande, pero falta acomodar los cuartos, pero si pudiera dar hospedaje, los cuartos tendrían que tener camas grandes y pequeñas para el gusto del turista, cada uno con su mosquetero, porque aquí en el tiempo de verano abundan los mosquitos, los cuartos tienen que tener buena ventilación, su televisor, baño..." (Margarita)

Como se puede evidenciar, los participantes tienen muy en claro cómo se deben preparar, para lograr atraer al máximo de turistas, proceso que requiere de preparación, conocimiento y práctica en cuanto a la alimentación, el alojamiento y un entrenamiento constante en el trato al turista. Como parte de dicho proceso, se requiere implementar además, espacios saludables, tanto para los visitantes como para la familia; en la siguiente subcategoría se muestra la inclusión de los baños dignos como parte de una vivienda saludable para el Turismo Rural Comunitario.

1.3 Mejora de espacios en la Vivienda Rural: Cocina mejorada y baños dignos

El saneamiento básico es una de las necesidades humanas esenciales cuyo disfrute universal no es una mera cuestión técnica, social o económica, sino un derecho humano. En la actualidad, más de 2,400 millones de personas en el mundo carecen de acceso a servicios de saneamiento adecuados y se ven obligadas a desechar sus excrementos en condiciones no mejoradas e insalubres ${ }^{17}$.

Desde hace 10 años el caserío Huaca de Piedra viene recibiendo el apoyo y trabajando en conjunto con diferentes instituciones privadas como: FONCODES y Centro ECO Perú, gracias a este 
esfuerzo, han logrado tener un baño que goza de mejores condiciones, una cocina mejorada que tiene un gran número de beneficios para la salud, reduciendo así los contaminantes en las viviendas.

La cocina mejorada es una tecnología que consta de una cámara de combustión y chimenea con capillas para extraer el humo de la vivienda. Al usar menor cantidad de leña, se reduce también las emisiones de gases de efecto invernadero (GEI) a la atmósfera. Además, ayuda a cumplir con los objetivos del milenio: Reducir la mortalidad infantil, promover la igualdad de género y empoderamiento de la mujer, generación de ingresos y erradicar la pobreza extrema, y el aseguramiento de la sostenibilidad ambiental ${ }^{18}$.

A continuación se presentan algunos testimonios que dan veracidad de lo que hoy es Huaca de Piedra como comunidad emprendedora, gracias a la implementación del TRC:

“.. La gente poco a poco ya quiere tener su cocina, su baño y su ducha, yo fui la primera que decidí poner mi cocinita, mi esposo hasta se molestaba, pero luego lo he llevado a las capacitaciones y ahora también es coordinador, ahora tengo cocina, baño y hasta ovinos de otros país que la ONG me trajo para poder criar..." (Líbido)

“...Yo era una de las personas que no quería saber nada de los proyectos, cuando me invitaban a las reuniones que centro eco tenía con todos los pobladores de por aquí, iba algunas veces pero no tenía interés en que me hagan baño o cocina, luego decidí probar con mi cocinita y me di cuenta de lo mucho que me sirve, si Dios quiere luego me inscribiré para que me hagan mi bañito..." (Flor)

Actualmente existe un programa de baños dignos destinado a resolver los problemas de agua y falta de saneamiento en comunidades indígenas $o$ rurales, que garantiza un sistema de baño en condiciones superiores a la de una letrina tradicional, trabaja en respuesta a los problemas de agua y a la falta de saneamiento en comunidades indígenas $\mathrm{y} / \mathrm{o}$ rurales. Los baños dignos es una propuesta de cuidar el ambiente y la salud, mediante el sistema biodigestor ${ }^{19}$. La satisfacción de la comunidad se presenta en los siguientes testimonios:

“...Tener un bañito ayuda en la familia, aunque los únicos que lo utilizamos son mi esposo y yo, nos da más comodidad y limpieza, da gusto de poder tener un bañito así, todos los días lo limpio, trapeo su piso..." (Azucena)

“...Yo quise que me hagan mi baño porque en mi casa somos 5 personas y tengo dos hijitos aun pequeños, asi que nos sirve mucho, el baño esta al fondo de mi casa y mi hija la mayor y yo somos quienes nos encargamos de limpiarlo siempre, me gusta que sea de mayólica y que cada día mi casa se parezca como de la ciudad... " (Rosa)

La vivienda saludable es una vivienda que sirve para brindar servicios sanitarios y sociales al turista. En tal sentido, las familias que deciden ingresar al programa, se aventuran en una nueva oportunidad de mejorar la situación socioeconómica de su familia, es así como surge el emprendedor dentro de la comunidad rural, con la guía y ayuda de los gestores. Esto se discute en la siguiente categoría.

\section{CATEGORIA II: GESTORES Y EMPRENDEDORES PARA EL TURISMO RURAL COMUNITARIO}

En el Perú estamos convencidos que el Turismo Rural Comunitario está basado en la gestión y participación organizada de las poblaciones locales tanto en el desarrollo de la actividad turística ${ }^{20}$. Un gestor es una asociación u organización local, gobierno regional y/o local, institución técnica de apoyo (ONG) u otro grupo de personas organizadas formalmente, que gestionan el desarrollo del turismo rural comunitario en un espacio territorial determinado ${ }^{21}$. Por otro lado, un emprendedor es una persona natural o jurídica que promueve un negocio o actividad productiva vinculada a servicios $\mathrm{y} / \mathrm{o}$ productos del turismo 
(alimentación, hospedaje, artesanía, guiado, arrieraje, etc.) ${ }^{21}$.

Los emprendedores en el caserío Huaca de Piedra, son las familias que se comprometieron con los gestores y hoy siguen trabajando con ahínco para desarrollar alojamientos turísticos, teniendo como principal atractivo su propia cultura, esto se discute en la siguiente subcategoría.

\subsection{Mostrando la cultura Viva: SICÁN}

La cultura Sicán, también conocida como Lambayeque, que significa "A imagen y semejanza de Naymlap o Ñamlap. Ésta cultura está representada por los objetos de oro, plata, cobre arsenical y tumbaga; textiles pintados y ceramios que provienen de las tumbas de elite de los Templos Mausoleos del Núcleo Cultural Sicán del Santuario Histórico Bosque de Pómac ${ }^{22}$. Hoy en día, se afirma que lo que identifica al oro sagrado del antiguo Perú en el mundo, tiene el brillo y magnificiencia de Sicán de Lambayeque.

Los pobladores del caserío Huaca de Piedra aún gozan y viven de esta cultura viva, pues ellos disfrutan mucho de la naturaleza y de su riqueza cultural junto al visitante. Los pobladores durante la afluencia de los turistas al Santuario Histórico, le brindan un circuito turístico que abarca el Museo Sicán en Ferreñafe, la Huaca La Merced y Huaca Las Ventanas; remontándose a la histórica cultura Sicán; reconociendo que la Cultura Sicán, es una cultura viva que aún permanece vigente, tal como se evidencia en los siguientes testimonios.

“...Cuando vengan a visitarnos los podríamos llevar a que conozcan el bosque de Pómac o las huacas arqueológicas, les daríamos un paseo para que vean las cosas que cosechamos, o los llevaríamos los viernes a reforestar así disfrutan de nuestro naturaleza que es puro y limpio..." (Flor)

“...Les enseñaría la naturaleza, lo tranquilo que es por aquí, que se vayan a pasear al Bosque de Pómac y que vean las aves que hay allí, le diría a mi papá que se vista como Señor de Sipán y que hable en idioma Mochica..." (Azucena)

Las personas de Huaca de Piedra mencionan, que recorrer el Santuario Histórico Bosque de Pómac es como hacer un viaje al pasado, pues generación tras generación vienen gozando de las riquezas de sus culturas, cuya satisfacción se ve irradiada en el orgullo que sienten al pertenecer a esa cultura y al hecho de aportar con el turismo en la zona.

“...Con centro Eco estamos quedando para que cuando vengan los turistas los llevemos a pasear en caballo, que utilicen las hamacas, llevarlos a que aprendan a cosechar, así como dice la señora "JMN" seamos su guía turística..." (Rosa)

“...Hemos formado una asociación, somos un grupo donde cada uno tiene su función, yo por ejemplo les doy la bienvenida a los turistas, tres mujeres de la asociación se encargan de preparar los alimentos, algunos más acompañan en el guiado turístico hasta el Bosque de Pómac, hemos decidido hacer caminata para que tengan la oportunidad de conocer y vivir más la naturaleza..." (Clavel)

Por otro lado, es muy importante el buen trato que se tiene que tener con la persona que visita el lugar. El mismo que se discute en la siguiente subcategoría.

2.2 Desarrollo de la capacidad de atención al turista

Para un desarrollo eficiente de la actividad turística, es necesaria la participación activa y permanente de los pobladores, ya que constituyen una pieza fundamental en el TRC, puesto que con sus actitudes y su trato va a generar una imagen en las personas que los visitan ${ }^{23}$. En tal sentido, el cambio de mentalidad juega un papel importante, pues se debe mirar al turista como el amigo, el hermano, al que se debe estimular y tratar bien para que se convierta en ente promotor en su lugar de origen y así se incremente el número de turistas que vuelvan a 
visitar. De esta forma se acrecienta la posibilidad de la creación de nuevos puestos de trabajo ${ }^{23}$.

“...Daría ofertas como por ejemplo, hospedaje incluido y que puedan pasear por las chacras y la naturaleza, así llamaría la atención de las personas que nos visitan; entre todas las que participamos, acordaría para tener equipado nuestro botiquín por alguna emergencia que tuvieran, eso le diríamos al turista para que esté tranquilo y sepa que le podemos dar primeros auxilios..." (Libido)

“...Vino un capacitador de Cuzco y en las reuniones nos decía que debemos darle confianza a los turistas, tratarlos con amabilidad, paciencia y cortesía, hay que tener buen carácter y humor, para que así se vayan contentos y puedan regresar..." (Clavel)

El respeto y la convivencia son factores claves para alcanzar el desarrollo sostenible de una región y es una característica que posee la gente del caserío Huaca de Piedra. Los testimonios presentados a continuación relucen el buen trato de un turista dentro de la comunidad:

“...Darles comodidad, tratar de que ellos se queden contentos y se diviertan y puedan satisfacer sus necesidades y se sientan felices en la comunidad, les daría mi confianza y así contarles de lo tranquilo y bonito que es vivir por aquí, que cuando se vayan al lugar donde viven puedan contar de todo lo que conocieron..." (Margarita)

“...Ya han venido turistas y se nota que les gustaba mucho el lugar, prometieron que iban a venir con sus familias y estudiantes, los hemos tratado con amabilidad $y$ hasta fotos nos tomamos con ellos porque uno llega a tener mucha confianza..." (Flor)

Se concluye, que recibir a los turistas con cortesía y amabilidad, mejora la percepción de los servicios brindados. Brindar buen trato al turista es una de las características del perfil de un emprendedor, lo cual se discute en la siguiente subcategoría:

2.3 Esbozando el perfil del emprendedor para el Turismo Rural Comunitario
Un emprendedor es aquel que se hace cargo de su propio destino y construye sus propios negocios. ${ }^{24}$ En Huaca de Piedra se pudo identificar a varias personas participantes con un perfil de emprendedor, su apoyo estuvo presente desde la programación de actividades hasta poner en práctica sus ideas espléndidas, demostrando capacidad y actitud para querer hacer bien las cosas no solo en beneficio a ellos mismos, sino también para la comunidad. Siempre demostraron responsabilidad, ganas de trabajar, ánimo y coraje. Luego de analizar la literatura, se muestran en escrito los testimonios dados por las familias:

“...A pesar que sufro de diabetes, me mantengo alegre, con energías y muchas ganas de trabajar, como verá siempre hago mis cosas, tener mi casa limpia... Preparo menú para unos trabajadores de la chacra, con ese dinero yo compro mis pastillas y los alimentos que hacen bien para mi salud..." (Libido)

"...Soy madre de familia soltera, vivo con mis padres que son ancianos y mi hijita que está chiquita, yo me anime a tener mi vivienda saludable y trabajar para el Turismo Rural gracias a los vecinos y a Centro Eco Perú, mi trabajo a diario en la comunidad es ir tres días por semana a reforestar, ser promotora de la vivienda saludable y apoyar en todo lo que yo pueda, me siento útil al participar, no falto a ninguna reunión de la comunidad..." (Flor)

La población de Huaca de piedra trabaja conjuntamente con la ONG Centro ECO desde ya hace algunos años; de allí que hay muchos pobladores del caserío que se desempeñan como líderes emprendedores en su comunidad, pues la ONG que es una institución que mira el desarrollo y la gestión sostenible de los recursos naturales y actividades de reforestación en la zona, siempre invita a los pobladores para que participen en proyectos de desarrollo, teniendo como premisa que el éxito en la comunidad no sería posible sin el fortalecimiento y apoyo de la estructura familiar y de los propios pobladores. 
“...Mi ganas de trabajar en la comunidad empezó por una necesidad, me decían que al trabajar con centro eco me traería trabajo y que iban a mejorar mi casa, ahora yo mismo he construido mi cocina mejorada y soy el encargado de construir, pintar y decorar las cocinas de las personas que viven en la comunidad y que trabajan en los proyectos..." (Clavel)

“...Yo quiero que mi comunidad esté bonita, apoyamos a la comunidad desde hace años, me siento importante y me gusta que mi lugar sea conocido por gente de otro país, y eso gracias a nosotros, porque al atender bien al turista, hemos hecho que Huaca de Piedra sea visitado..." (Margarita)

La siguiente categoría muestra las contribuciones que pueden lograr las familias de Huaca de Piedra gracias al Turismo Rural Comunitario y a una Vivienda Saludable.

\section{CATEGORIA III: CONTRIBUCIONES DEL TURISMO} RURAL COMUNITARIO Y LA VIVIENDA SALUDABLE A LAS FAMILIAS DEL CASERIO HUACA DE PIEDRA

Esta relación, contribuye al reforzamiento de la identidad e institucionalidad local, une a la biología, antropología, sociología rural, arqueología para poner en valor el patrimonio cultural y natural. Además, esta relación supone un aliciente para la recuperación y conservación de la arquitectura tradicional, su ingeniería, y el medio ambiente, además de mejorar la calidad de vida de cada una de las familias que habitan en las viviendas 24 . A continuación se describen las contribuciones a manera de subcategorías y en forma más detallada.

3.1 Beneficios económicos del emprendedor turístico:

La vivienda saludable a través del TRC pone a disposición de los turistas tanto nacionales como extranjeros, una oferta de servicios que viene a incrementar la rama económica en las familias; por lo tanto, constituye un valor importante. A la vez genera empleo, representando así una alternativa de ingreso para la población en edad de trabajar y que pertenece a las comunidades donde se han establecido estas viviendas saludables ${ }^{21}$.

Las familias de la comunidad Huaca de Piedra son consideradas aún en línea de situación de pobreza, algunos con escasos fuentes de trabajo y poca valoración de sus recursos naturales. Con sus viviendas saludables se busca mejorar la calidad de vida de las familias de ésta comunidad; a través del mejoramiento de sus condiciones de habitabilidad al turista, desarrollo de actividades productivas rentables y conservación del medio ambiente. Uno de los resultados que desea es un incremento de su economía.

“...Mi casa por ser grande ayuda al turismo a que aquí se puedan hacer las reuniones con todos los pobladores, sé puede cocinar cuando vengan los turistas, ya que tengo dos cocinas, yo aprovecho en vender mis frutales cuando se hacen reuniones, tengo nuevos ingresos..." (Azucena)

"...Cada vez que lleguen los turistas tienen la posibilidad de visitar mi casa, ya que queda en la entrada del caserío, eso es una oportunidad para mí ya que tengo una pequeña tiendita que al ser visitada por los turistas me daría más ingreso, mi casa la pueden visitar a cualquier momento señorita es muy limpia y ordenada..." (Flor)

Como podemos observar, el TRC incrementa la posibilidad de generar ingresos económicos para las familias, quienes aprovechan para ofertar sus productos locales, así como otros de primera necesidad en estos casos. Esto aunado a los beneficios ambientales que disfruta la propia familia por el mismo hecho de contar con una vivienda saludable, lo cual se discute en la siguiente subcategoría.

3.2 Beneficios ambientales con una vivienda saludable:

La vivienda, como beneficio ambiental es adecuada para el desarrollo social y psicológico de las personas y minimiza las tensiones psicológicas y 
sociales relacionadas con el entorno. Entre los impactos positivos de la vivienda y su relación estrecha con el TRC destacan, el despliegue de satisfacciones biológicas, estéticas, de la información y la comunicación, así como la facilitación de la educación, las labores domésticas y el desarrollo de la familia ${ }^{25}$. La población Huaca de Piedra expresó lo siguiente:

"...Somos ya varias familias que tenemos vivienda saludable, esperemos que los demás se animen y se unan al programa, ahora que las casas están pintadas con dibujos de la cultura y tienen sus baños y sus cocinas, hace que nuestra familia viva mejor, sin preocupaciones, estoy feliz..." (Libido)

“...El caserío Huaca de Piedra antes era olvidado, el nuevo alcalde cada vez que nos visita se asombra de cómo estamos cuidando el lugar; yo me siento feliz con lo que hemos logrado, me da gusto que autoridades nos tomen en cuenta para los proyectos que se realizan aquí..."(Flor)

Las familias de Huaca de Piedra han alcanzado gran satisfacción en su vida personal y colectiva, y siguen trabajando activamente, para llegar a tener un desarrollo sostenible, capaz de satisfacer absolutamente todas sus necesidades, en pro de su desarrollo familiar, mejorando con ello a demás su situación de la salud familiar y comunitaria.

\section{Consideraciones finales}

Las familias del caserío Huaca de Piedra- íllimo, cuentan con una vivienda rural saludable, incluyendo la implementación de cocinas mejoradas y baño con sistema biodigestor, con ello tienen la posibilidad de brindar servicios de alimentación y alojamiento digno, para el Turismo Rural Comunitario.

La oportunidad de ubicarse en la zona de amortiguamiento del Bosque de Pómac está desarrollando un constante aprendizaje en sus pobladores para el Turismo Rural Comunitario, al tener que mostrar y valorar su cultura, motivar a las familias a brindar un buen trato al turista, para lo cual están desarrollando nuevas capacidades, como el de ser guía turística, ofertar productos de la zona, entre otras, a pesar de ser una iniciativa reciente.

Las Familias del Caserío Huaca de Piedra han encontrado un proceso de interacción muy positiva, entre la vivienda rural saludable y el TRC, toda vez que están percibiendo beneficios sociales, económicos y ambientales, además de la generación de entornos saludables.

\section{Bibliografía}

1. Resumen del informe sobre salud en el mundo: La atención primaria de salud, más necesaria que nunca. Estados Unidos: OMS; 2008

2. UNICEF. Niños y adolescentes indígenas del Perú son pobres. La República, Perú: 2010, agosto 19. http://www.larepublica.pe/1908-2010/unicef-78-de-ninos-yadolescentes-indigenas-de-peru-sonpobres

3. Díaz M. Modificando las condiciones de vida de las Familias Campesinas de Íllimo a través de la Atención Primaria Ambiental. Lambayeque-Perú; 2009

4. Díaz M. Vivienda Rural Saludable. Centro ECO, Lambayeque-Perú; 2008

5. Bernal C. Metodología de la investigación. $2^{\mathrm{a}}$ ed. México: PEARSON; 2006.

6. Polit H. Investigación científica en ciencias de la salud. Principios y métodos, 6ta edición, México; 2000.

7. Atlas del Departamento de Lambayeque. Premio Internacional Educared. Perú; 2011.

8. Santiago M. Principios, métodos y técnicas esenciales para la investigación educativa. 1 ed. Madrid: Editorial Dykinson; 2010. 
9. Pineda B. Canales metodología de la investigación: Manual para el desarrollo de Personal de Salud. 2 ed. Washington; 1994.

10. Polit D y Otros. Investigación Científica en Ciencias de la Salud. 4 ed. México D.F: Mc Graw Hill Interamericana; 2000.

11. Mujica M. Hacia el cumplimiento de los Objetivos de Desarrollo del Milenio en el Perú: Un compromiso del país para acabar con la pobreza, la desigualdad y la exclusión. 1 ed. Perú: Grobel; 2004

12. Ministerio de Salud. Programa de familias y viviendas saludables. Perú: MINSA; 2006. Disponible en:

ftp://ftp2.minsa.gob.pe/descargas/dgps/ compendio/pdf/170.pdf

13. Caldera Y. Del fogón a los tecnoalimentos. Caracas; 2010.Disponible en: http://www.docstoc.com/docs/35269894 /Del-fog\%C3\%B3n-a-los-tecnoalimentos

14. Caritas del Perú. Loche de Lambayeque: Manual de Cultivo. 1 Ed. Perú: Impactum Creativos S.A.C; 2012. Disponible en: http://www.caritas.org.pe/documentos/lo che.pdf

15. Achá C, Llorca J, Pereda V, Valdez E, Carámbula L, et al. Manual para manipuladores de alimentos. Montevideo: IMM; 2006. Disponible en:

http://www.montevideo.gub.uy/tramites/ sites/montevideo.gub.uy.tramites/files/for mulario_tramites_servicios/manual_manip uladoresalimentos_1_0.pdf

16. Ministerio de Comercio Exterior y Turismo. Reglamento de Establecimiento de Hospedaje DECRETO SUPREMO $\mathrm{N}^{\circ} 029$. Lima: MINSA; 2004. Disponible en: http://www.mincetur.gob.pe/newweb/Port als/0/REGLESTAB_HOSP_2004.pdf
17. Mancisidor M. El derecho humano al agua: Situación y retos de futuro. 1 ed. Vasco: Icaria; 2008.

18. Leyva S. Manual de construcción de una cocina mejorada para la zona rural. 1 ed. Perú; 2010.

19. Ministerio de Salud Perú. Ley general de servicios de Saneamiento. Lima: MINSA; 2000.

20. Ministerio de Comercio Exterior y Turismo. Lineamientos básicos para la formulación de proyectos de inversión pública en emprendimientos de turismo rural comunitario. Lima: MINCETUR.

http://www.mef.gob.pe/contenidos/inv_p ublica/docs/normas/normasv/snip/a2013 LAnexo-RD-005-2013.pdf

21. Ministerio de Comercio Exterior y Turismo. Manual del emprendedor en Turismo rural comunitario. Lima, Perú: MINCETUR; 2008. Disponible en:

http://www.bvcooperacion.pe/biblioteca/ bitstream/123456789/6434/1/BVCl0006 643.pdf

22. Servicio Nacional de Áreas Naturales Protegidas por el Estado. Plan Maestro Santuario Histórico Bosque de Pómac 2011-2016. 1 ed. Lima: Sernamp; 2011.

http://www.sernanp.gob.pe/sernanp/arch ivos/biblioteca/Bosque_de_Pomac/PLAN_ MAESTRO_SHBP_2011-2016.pdf

23. Torrejón A. Por una mayor conciencia turística, en el camino al bicentenario. Argentina; 2008. Disponible en: http://www.cienaniosdeturismo.gov.ar/up loads/file/032boletin 100a\%C3\%B1 os.pdf

24. Ministerio de Comercio Exterior y Turismo. Manual del emprendedor en Turismo rural comunitario. Lima, Perú: MINCETUR; 2008. Disponible en: 
http://www.bvcooperacion.pe/biblioteca/ bitstream/123456789/6434/1/BVCI0006 643.pdf

25. Organización Panamericana de la Salud (OPS). Hacia una Vivienda Saludable- Guía para el facilitador.1 ed. Perú: SINCO; 2009. Disponible en:

http://www.paho.org/per/index.php?gid= $\underline{68 \& o p t i o n=c o m \_d o c m a n \& t a s k=d o c \_v i e w}$ 